\title{
Conservation Committee Report to the Annual Meeting of the S.N.H.S.
}

By Fred G. Bard, Sask. Museum of Natural History.

\section{REGINA WATERFOWL PARK}

The Regina Waterfowl Park is feeling the pressure of rapid city development. Contacts have been made with the City Commissioner, John Steel, and the Parks Superintendent, William Murray; both are in sympathy with park policy, but are often not even informed of the dumping of soil, cement blocks and other debris from construction which destroys the grass cover and leaves an eroding slope. Much money and man-power will be required to rerabilitate this area as a formal park instead of the intended natural marsh waterfowl park. The present boundaries are less than half of the original Wascana Game Preserve, and the remaining half seems now to be disappearing.

In spite of these changes, the Canada Geese without any management had 31 nests this year, mainly in the vicinity of the Goose Island, with. 103 birds being raised ( 52 banded by Ducks Unlimited, Natural Resources and Museum personnel). Most people are genuinely interested in the geese, but a few are only interested in shooting them, so we have appealed to E. L. Paynter, Director of Wildlife, to approach Ottawa to see if shooting can be prohibited in the two (city) townships 19 and 20 , range 17.

Four geese were given to the waterfowl park this year by Mrs. W. Keebeck of Foam Lake. The Keebecks raised these birds in 1954, and Mrs. Keebeck has written us about their experiences with them, as follows: "In 1954, the year of the high water level, my husband knew of three pairs of Canada Geese nesting near a large slough .... After a heavy May snowfall the nests were washed out except for six eggs that he managed to save and brought home to put under a hen ... Four of the goslings lived ... a and I clipped their wings before hunting season. ... However, I didn't like to think of some hunter having easy hunting at our slough, so after the first year I

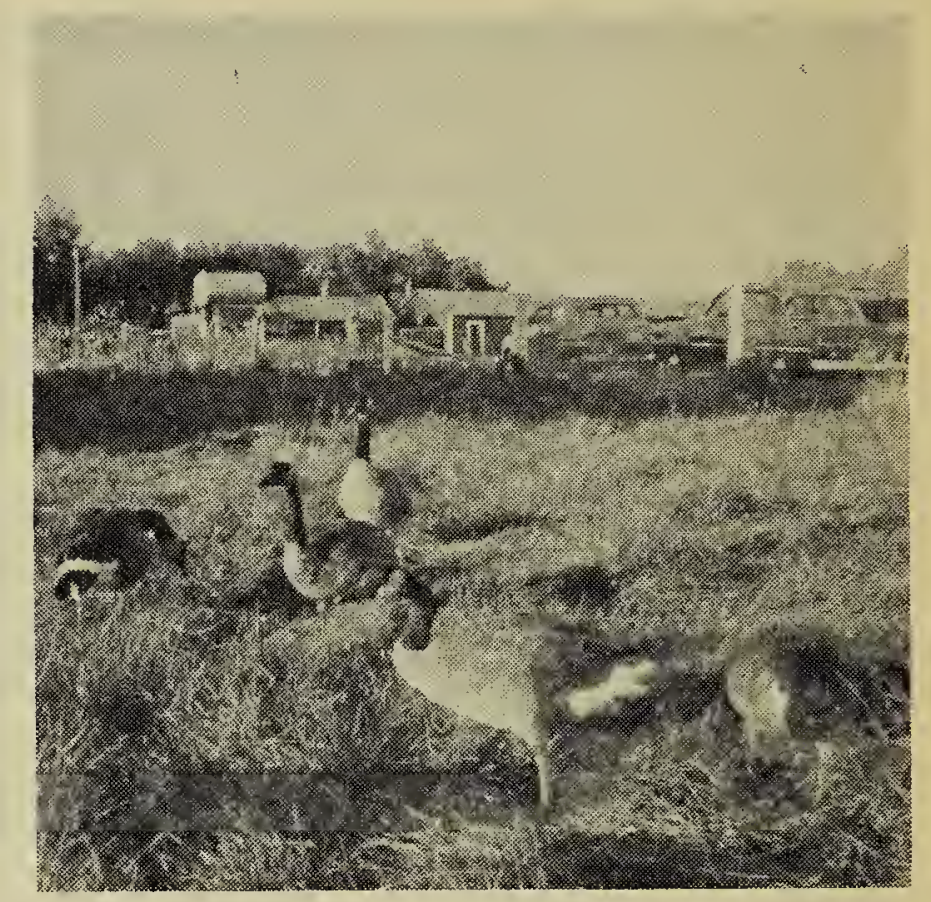

only clipped one wing and left them free to fly. None of the eggs laid in the past three years has been fertile except for the eggs laid by a goose which this last year mated with a wild gander that stayed in the yard with her . . ." The accompanying photo shows the geese at Mrs. Keebeck's home.

The lowering water table destroys beds of cattails and bulrushes and reduces the cover suitable for blackbirds, etc. The water situation became very serious this year, but heavy fall rains have restored the water level adequately.

MARTIN HOUSES IN REGINAThree apartment-type martin houses were donated to the Museum by the Regina Fish and Game League and the Regina Natural History Society. Two were installed in Wascana Park adjacent to the Museum and one in front of the Geriatric Centre in the Legislative Grounds. One installed in time for the nesting season, was occupied in a few days; the others were put up chiefly for public interest and the A.O.U. conference.

WHOOPING CRANES - Records for 1959 are rather unsatisfactory. The rapid change in weather and early snow seems to have caused the birds to move earlier than usual. The first two arrived in Aransas 10 
days to two weeks earlier than normal. In the fall migrations single birds were seen in three different areas, two of which could have been the same bird. The best record was from Richard where a pair with one young was seen on October 7. During the summer aerial surveys on the nesting ground, only two young were seen. It's too early to say what the winter count will be, but it doesn't look encouraging as the average annual loss seems to be close to four birds.

The New Orleans captive bird laid seven eggs, but reared no young. Here again we are wasting valuable time by not managing the present flock. There have been so many successful avicultural programmes that we believe someone with the necessary "know-how" should be asked to advise on a whooping crane programme. At present the whole whooping crane programme consists in tracking their movements and encouraging safe passage along the flyway. Without authority and support, we can only wait and see whether the cranes escape the heavy toll twice before taken of their numbers.

PARKS A N D WILDERNESS AREAS-It is encouraging to see the province setting up new areas for recreational use. Every individual landowner, too, should be urged to help preserve wilderness areas for recreational use and for study (at both popular and scientific levels). The conservation committee does not function for itself but rather to encourage everyone to participate in conservation. We should like all interested people to keep us informed of projects or continuing programmes as well as individual efforts. When this information is made public others are encouraged to give similar support.

\section{Red Crossbills Feeding on Aphids}

\section{By G. F. Ledingham, Regina}

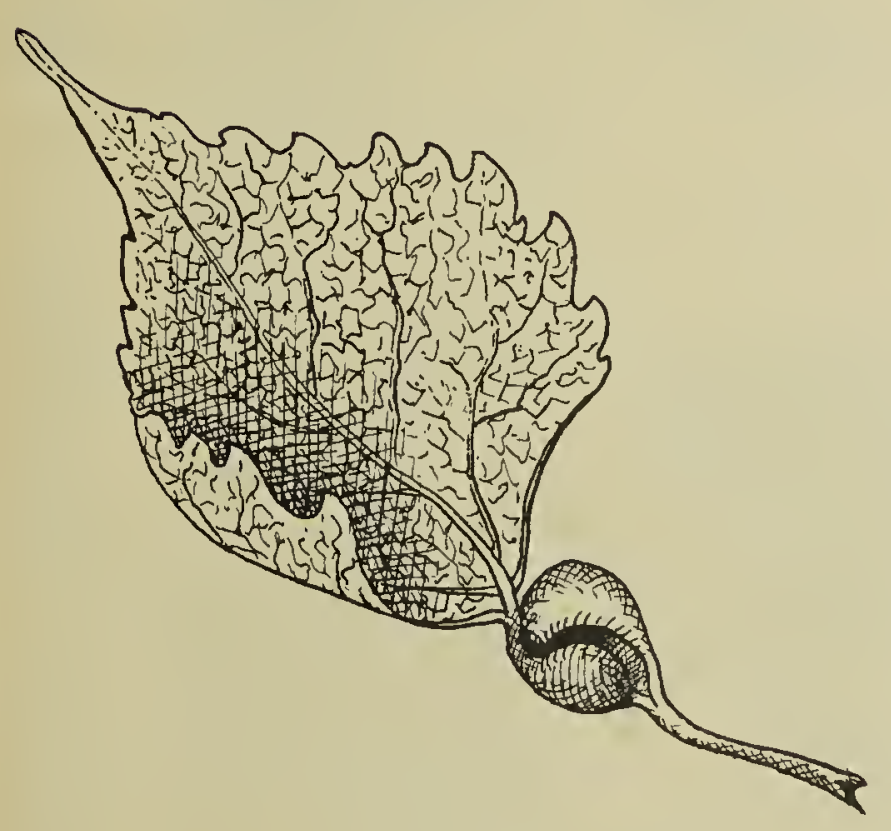

Sketch by L. Ostoforoft

On July 29, 1959, I stopped at noon under three old eastern cottonwoods (Populus deltoides Bartr. ex Marsh.) which grow in front of our house in Regina. Tr.ere was a familiar but.unexpected chattering of birds above me. Soon I saw a male Red Crossbill (Loxia curvirostra) in full plumage. My wife, Betty Cruickshank and Arthur Taylor soon joined me and we saw about ten crossbills in various plumages.

The interesting thing to me was first that they were here in Regina in July, second that they were in poplar trees. I had never trought of the crossbill as feeding on anything but the seeds of conifers. These crossbills were contentedly feeding in poplars in July. I watched the male snip into a leaf gall, obviously feeding on the insects within the gall, and then go on to the next gall. All the birds were feeding in the same way. Sometimes the leaf would break off at the gall and come floating down. A couple of hours later there were over 200 of these leaves on the ground and the crossbills had moved on and were not seen feeding here again.

Mr. Lloyd O. T. Peterson, entomologist at the Research Branch, Canada Department of Agriculture, Forest Nursery Station, Indian Head, kindly identified the insect for me as the poplar aphid, Pemphigui populicaulis Fitch. "Its galls are subglobular. They always occur at the base of the cottonwood leaf and the opening in the gall is oblique. No 